\title{
Translators Producing Knowledge: Where There Is No Doctor in Tamil
}

\author{
LILLIAN WALKOVER \\ DREXEL UNIVERSITY
}

\begin{abstract}
Where There Is No Doctor is one of the most widely used community health books in the world and has been translated into over 80 languages. This paper traces four aspects of translation in Tamil-language editions of the text, including Doctor Illaadha Idaththil and related books. First, translators choose and create language to produce a colloquial text related to, but different from, the original. Second, the translated text, as part of a genre of health writing, is edited to motivate readers to take new and different actions related to their bodies and wellbeing. Third, the success of this work is assessed by asking future readers to respond to the draft. Finally, the finished translation circulates to new arenas, influencing popular writing on health and ways of understanding the body. Analyzing the translation of a health text through the lens of postcolonial translation studies, this paper argues that the translation and adaptation of Where There Is No Doctor and the books it inspired engage translators, clinicians, and future readers in a transnational knowledge production process.
\end{abstract}

\section{Keywords}

postcolonial translation studies; postcolonial STS; sociology of knowledge; critical global health

\section{Introduction: Producing Knowledge Across Difference}

Sadhiq and Nisa are a husband and wife who run a non-profit publishing house in Tamil Nadu, India. Sadhiq became a publisher after training as a pharmacist. Nisa trained as a nurse and assists with translating publications related to health. In 2011, the two collaborated to translate the international community health book Where There Is No Doctor into Doctor Illaadha Idaththil (țākțar illāta ițattil) ${ }^{2}$ for use by Tamil-speaking villagers, community health workers, and clinicians. In an interview, they describe how they developed new language while translating:

'Lillian Walkover, Email: lbw36@drexel.edu

2 I have chosen to use a lay version of phonetic writing to represent Tamil words in this paper in order to facilitate reading for people who do not speak Tamil. Select words for which a lay spelling is ambiguous have been provided in formal diacritic marks in parenthesis to clarify pronunciation. The spellings used were given by participants, who are translators fluent in both Tamil and English, with some adjustments for ease of reading in consultation with Dr. Vasu Renganathan.

Copyright (C) 2019 (Lillian Walkover). Licensed under the Creative Commons Attribution Non-commercial No Derivatives (by-nc-nd). Available at estsjournal.org. 
Nisa: "Edema" does not have a word in Tamil. It is a collection of liquid in one particular part of your body. People were always calling it "swelling." How can you call it a "swelling"? It's wrong. And you will give a wrong thing. The person will say he doesn't have any swelling. He doesn't know it's edema. So, we thought about a word, "niirviikkam," that is "water logging." In one of your body parts. We basically picturized things, animated it and brought out our [own word].

Sadhiq: It's people's language.

Nisa: Colloquial words. Which you can just polish and make a textbook word.

Sadhiq: There are so many words-

Nisa: Words which are commonly used by common people. These words will stay in a village health nurse's mind. Even if she's read the book once, she will know somebody with kidney failure who is progressing will have... "niirviikkam." She will know "water logging." So yes, [she] must send this person to the Primary Health Care Centre.

Around the world, global health workers try to achieve what Nisa imagines: a villager knowing when to seek care, and a nurse knowing when to refer that patient to more advanced care. However, they rarely assume that villagers can understand their own body, or that rural clinicians can understand the promise and limits of biomedicine. They also rarely acknowledge the importance of knowledge produced outside the American or European core. Sadhiq and Nisa address the villager and health worker directly, and in the process, create new vocabulary that produces new understandings and actions.

In this paper I argue that the translation and adaptation of Where There Is No Doctor and the books it inspired engage translators, clinicians, and future readers in a process of transnational knowledge production. My analysis situates the production of the translated Tamilian health books as important examples of knowledge production at multiple levels: for and by the translators, in interaction with the labor of eventual readers and users, and for the development of the Tamil language. I underline the importance of knowledges that are produced in what are usually considered the margins, demonstrating how such knowledge production is central to global health. I analyze four aspects of translation and the health knowledges produced in the process from the perspective of the translators. The first is finding language that is legible to readers and listeners with limited formal education, making understanding possible through a text both distinct from and related to previous versions. The second is finding language that will create opportunities for readers to act in new ways. The third is assessing the relative success of these efforts by engaging with readers and inviting them to participate in editing the text. The fourth is circulating new vocabularies with and beyond the books themselves. To analyze these processes, I draw on postcolonial translation theorist Sakai's argument that:

Through the translator's labor, the incommensurable differences that call for the translator's service in the first place are negotiated... In this respect translation is like other social practices; translation makes something representable out of an unrepresentable difference. (Sakai 2006, 75-my italics) 
As Morris argues, Sakai draws on "a conception of translation as a practice producing difference out of incommensurability (rather than equivalence out of difference)" (Morris 1997, xiii; Chakrabarty 2000,17). This contrasts with other literary views of translation as the creation of equivalence between two different words. Sakai and other postcolonial translation theorists point out that translation produces a new representation that was not previously conceived of. One concrete example of this is contained in the exchange between Nisa and Sadhiq shown above: while translating, they chose not to use the previously-used word "swelling"--but instead created a new word ("niirviikkam") that they hoped would create new understandings and actions among Tamil-speaking readers.

Drawing on the work of Sakai, Morris, and others, this analysis builds a sociology of health knowledges produced in translation and contributes to debates about the ongoing creation of different kinds of knowledge. Translation studies has emerged over the past half century (Gambier and van Doorslaer 2010) at the juncture of literature, history, cultural studies, and social sciences. The sociology of translation, a subfield, ${ }^{3}$ has emerged in the past two decades (Wolf and Fukari 2007), focused on the analysis of written and verbal translation. Much of the work in this subfield has focused on dynamics of international book markets, hierarchy of languages, and identity of translators-the social and structural relations of production-and does not provide sufficient analytic leverage for conducting the micro-level investigation of language choice and creation that this paper engages. However, one branch of sociology of translation provides part of this needed leverage: Latour's (2007) Actor-Network Theory (ANT) brings in books as non-human actors (Buzelin 2007). ANT was originated by Latour, Callon, Law and colleagues in the 1980's to argue against previous approaches that did not account for the role of non-humans in social action. Latour advocated for an approach that identifies non-human as well as human actors and lays out the network of relationships between them.

Engaging an ANT analysis for this project centers the books and focuses on stabilization created through the network and the objects' immutability as they travel. This turn towards STS (science and technology studies) perspectives in the sociology of translation is promising but its assumption of immutability is problematic. Studying the translation of Where There Is No Doctor to create Doctor Illaadha Idaththil from a postcolonial standpoint enables us to recognize that translation is an important location of knowledge production-not an instance of "catching up" with knowledge that was produced in and by the former settler colonies of "the West," but rather an instance of producing crucial health information that is relevant to the lived experiences of future readers.

Where There Is No Doctor and its companion books are intentionally mutable and invite change as they travel. They are also health materials, and as such are part of a category of writing intended to inspire action, impact bodies and improve health. They travel with, across, and despite colonial agents, making a postcolonial lens crucial for a sociology of translation with

${ }^{3}$ Sociology of translation can be understood as a broad field investigating the concept of translation. This paper focuses on sociology of translation as a sub-field of translation studies and on written and verbal translation of language. 
respect to these texts. ANT has been criticized for lacking a postcolonial perspective (Anderson 2009) and for flattening power dynamics and the social hierarchies that maintain them (Clarke, Friese, and Washburn 2017; Star 1990). I therefore extend an ANT treatment of translation by taking up postcolonial translation studies to argue that translators are a key part of the knowledge production process. This analysis in turn provides important contributions to how we understand health knowledge production more broadly.

This paper begins with a brief background on Where There Is No Doctor and related books, focusing on their translation into Indian languages. Next, I explore how the books' Tamil translators choose, create, and test language intended to reach audiences with limited formal education and motivate readers to act. This leads to a discussion of how language travels to broader audiences. I argue that this translation is part of the knowledge production process: it is not the "creation of equivalence" in which prior knowledge is simply reproduced, but rather the creation of a new text both distinct from and related to previous versions. Far from representing the same text in another alphabet, these translations are a key part of the production of health knowledges, codified in new language and making new forms of action possible.

\section{Background}

Donde No Hay Doctor was published in 1973 based on the combined efforts of American volunteers and Mexican community health workers and inspired by Paulo Freire's (1970) pedagogy of popular education. It was translated into English as Where There Is No Doctor in 1977, and Hesperian Health Guides was established as a non-profit publisher in California to distribute the book. Using an open-copyright model, translation and adaptation of the book were encouraged, and for the next forty years the book, as well as excerpted images and ideas from the text, traveled around the world from Zimbabwe to Antarctica (Hesperian 2013). Since the publication of Where There Is No Doctor, Hesperian has published eleven additional community health books, which have been translated and adapted into over 80 languages. The book is written for audiences who have received limited formal education and heavily illustrated in the hope that an illiterate villager could find the information useful if it were read aloud by a community health worker or neighbor with a few years of formal education. The back covers of the American English editions (Werner, Thuman, and Maxwell 2009) state that the book is for villagers, village storekeepers and pharmacists, teachers, village health workers, and mothers and midwives. The book "explains in simple words and drawings what [they] can do to prevent, recognize, and treat many common sicknesses." These ideas travel with the book, across continents, languages, and time, with a focus on sharing knowledge, and on acting on both individual and community levels.

Where There Is No Doctor was first adapted for India in 1980 by the Voluntary Health Association of India (VHAI), a national non-profit that distributed the book throughout the country. With re-drawn illustrations to show men and women in Indian clothing, and revised lists of herbs and pharmaceuticals, VHAI's English-language Indian adaptation was quickly taken up by groups training community health workers. However, to reach Indians across 
different states and language groups, ${ }^{4}$ translators emphasized that having a book available in the colonial English language would not be sufficient: it must be available in regional languages that many people understand more intuitively. The book has since been translated into eight major Indian languages. Doctor Illaadha Idaththil was one of the first translations, published in Tamil in 1984, and remains in print.

Tamil translations make an excellent case study for this paper from both a linguistic and health perspective. Tamil dates from the $5^{\text {in }}$ century BCE; it is the official language of the southern state of Tamil Nadu, and is spoken by more than 66 million people around the world (Krishnamurti 2011). There is great pride in Tamil language and literature, which has been maintained through colonial rule and the designation of Hindi and English as the official languages of the government of India. Since 1984, there have been numerous Tamil translations of Where There Is No Doctor and related books, many of which remain in circulation. While the Tamil language makes an excellent "ideal" case language, and the rich history of both community-based and government health programs in the state of Tamil Nadu make it an excellent location for examining the production of health knowledges, these books are atypical among widely translated works. Where There Is No Doctor and its companion books are meant to be read as references for practical purposes: the intended reader reads them, sets them down, and proceeds to take specific actions for their own health or that of those in their care.

In global health, the "global" text or practice is generally produced in the European or American core and distributed as a hegemonic solution, while "local" adaptations or indigenous versions of a similar text or practice stay on the periphery (Biehl and Petryna 2013). The theoretical tools of a sociology of health knowledges produced in translation developed in this paper center the translated object-in this case, Tamil language books-rather than the internationally-used American English edition. The analytic importance of this step, and of engaging postcolonial theory for this analysis, is underscored by the history of the book. The American English edition functions as an intermediary form that travels postcolonial tracks to connect community health workers in the mountains of Mexico (where the book was written in the Spanish of the colonizers), through the settler colony of the US to post-independence India and the state of Tamil Nadu. This intermediary version allowed people across Tamil Nadu to learn from mountain villagers in Mexico, in a process that reflects Tsing's (2005) concept of global friction: neither a clash of civilizations, nor a smooth and uninterrupted flow of knowledge around the world, but a series of interactions between variously situated actors that produces and re-arranges the social world. That is, the American English edition as intermediary does not travel because it is universal or not-local. Rather, it traveled to Tamil Nadu because of the histories of colonialism that resulted in English being the dominant language in the United States and a language that is also widely spoken in India, especially by the upper classes. Taking this into account, focusing on the translated book allows us to focus on knowledge production in Tamil translations while recognizing the heterogeneity of language use within India.

\footnotetext{
4 Twenty-two languages are officially recognized in the Indian constitution, and hundreds of additional languages are spoken throughout the country (Census of India 2011).
} 


\section{Methods}

This paper draws on a subset of 11 interviews related to Tamil translation from a larger project on Where There Is No Doctor and related texts. Data for the full project were collected during 20132017 and included 63 interviews with participants involved in the translation, adaptation, distribution, and use of books published by Hesperian Health Guides—notably the book Where There Is No Doctor--into Tamil, Kannada, Hindi, and English, for use in India. Participants included medical doctors, public health professionals, social workers, and publishers. Interviews were transcribed, reviewed, and coded. Participants gave their informed consent to be interviewed and are referred to by their names or pseudonyms, depending on their preference. I also observed publishers and community health worker trainings and work, and analyzed written materials, including translations and adaptations, draft materials, and related writing on community health workers. Analysis was conducted using a constructivist grounded theory methodology (Charmaz 2014).

\section{Language Should Be Simple Enough for Everyone}

According to the translators, language used in and created for these books must be something that the reader will understand. In the opening vignette, Nisa and Sadhiq discuss the importance of choosing and creating language that anyone can understand. If technical vocabulary that is not descriptive of someone's experience is used, Nisa warns, "the person will say he doesn't have any swelling." Instead, language is needed that can help people connect an idea about health to their own experiences and body. This language is available, they argue, in the form of "colloquial words which you can just polish and make a textbook word." They "polish" language, creating new vocabulary out of familiar phrases, and publishing it in a widely read and distributed book so that people will better understand their own health. While some people using the book have formal health training, it is written to be read by anyone, and to be understood by illiterate listeners. The translators are highly educated people who know the way they read, speak, and listen may be very different from the imagined audience they are committed to reaching. They address this distance in two related ways: by distinguishing between "high" Tamil and the kind of language people speak every day, and by focusing on functional, as opposed to literal, translation. Sakai writes that "translation is often represented as a process of establishing equivalence" (Sakai 2006, 71). In such a frame, crafting a comprehensible text might be seen as creating access to existing information in a new language. In contrast, these authors recognize and actively work across distance to reach audiences who differ on class, caste, linguistic, literacy, educational and other lines.

The first way translators address the distance between themselves and readers is to use "low" rather than "high" Tamil. Translators frequently mentioned widespread pride in Tamil literature and language. They also discussed the distinction between "high Tamil," used in formal writing, and "low Tamil," spoken colloquially. Helping Children Who Are Blind was co-

${ }^{5}$ I was employed by Hesperian for five years; memos from these periods include reflexivity about my roles. 
authored by Namita Jacob, a Tamilian woman; she later oversaw translation and adaptation efforts in India. In a pattern that was common across many books, a professional translator completed an initial Tamil translation. Next, the text was edited by a team of volunteers led by Namita. One of the volunteers was a woman I will call Seetha Raman, who spent years recording and transcribing papers, books, and magazines for blind students. The role of the volunteers was to shift the level of language, from the high Tamil it had been translated in, to words anyone might understand. The translation team broke up long sentences into shorter ones. They changed the level of the vocabulary, because as Seetha says, "even for a father there are different words. There is 'thandhai,' which is a word that is normally used, but I found 50 percent didn't understand it. So appaa, you know appaa is what we call the father." So they used the more common appaa for father, rather than the formal thandhai. In many ways, this seems like an obvious choice, but it reflects an active effort to push back against strong social pressure among the highly educated classes to maintain and promote high Tamil.

Ramakrishnan, who published the first Tamil edition of Where There Is No Doctor in 1984, talks about the pressure to use high Tamil vocabulary, and his counter-insistence on using language that most people will understand:

We are totally against that kind of high style puritanical approach. In using Tamil words, very often we used what an illiterate person would use in a village. For example, a woman in a remote village, she may not know the word we use. We used terms which people were using because it is communication which is important: language should be simple enough for everyone.

As an educated man and professional publisher, Ramakrishnan speaks both fluent English and a different style of Tamil from "a woman in a remote village." However, he distinguishes himself from "puritanical" writers and publishers primarily concerned with maintaining high Tamil as the standard for publication. He positions himself instead as someone able to act as a bridge--capable of translating a six-hundred-page book, but also able and willing to use vocabulary that illiterate people would understand. Translation, as Ramakrishnan describes it, inherently engages contestations over the use and development of Tamil language. He acknowledges both his role as a potential bridge, and the social distances between an illiterate villager and a publisher dedicated to the maintenance of high Tamil. This distance, he notes, is across such a steep social hierarchy that many of the words one person uses would be incomprehensible to the other. If Ramakrishnan published a high Tamil translation of the text, it would be functionally useless; the intended audience would not be able to read or understand a significant portion of the text. In the context of the politics of maintaining the Tamil language, the choice to publish a low Tamil text is a political and conscious one, reaching across difference to produce a kind of text that would not otherwise exist: a formal publication in an informal iteration of the language.

Saulina translated the 1998 Tamil edition of Where There Is No Doctor for the state affiliate of VHAI; this involved both updating Ramakrishnan's earlier Tamil edition and translating the updated English-for-India book. As a highly literate woman, she is capable of reading and 
translating from English to Tamil but chooses Tamil vocabulary she hopes will be understood by people with much less formal education. Saulina's concern about creating a functional translation reflects the stratification of the society in which she lives. This interest in translating into "low Tamil" is in turn reflected in the second mechanism for addressing this social distance, which Saulina describes as focusing on functional, as opposed to literal, translation. In contrast to the process described above, Saulina completes the first draft of the translation herself, and then launches into a related process of gathering feedback (as discussed further in the third section of the analysis) from medical and non-medically trained colleagues, including community health workers and the people they work with:

It is not just a translation. I do functional translation, not literal [translation] ... because the main aim we have is to communicate the concept to people. Not just to have a literally, literature, I mean literal book, with high Tamil or anything. I always fought with it and that is how I am still doing translation.

Here she associates "high Tamil" with literature and with literal translation, explaining that she "fights" to create what she calls a functional translation. As she puts it, functional translation "means it is something that people can understand. Some of the words we had to adapt, to make sure that people understood the functional terms. We are not going to be there when they are reading it, so it should be self-explanatory." Her immediate concern as a translator is that when readers pick up the book, they should be able to understand the words on the page without further explanation. A literal translation would attempt to create equivalence from the difference between a mono-lingual Tamil speaker and the English-language page. In contrast, what Saulina focuses on in her translation can be related to what Morris describes as creating difference out of incommensurability through functional translation: creating difference by selecting language that supports people from different educational and linguistic backgrounds to understand the text.

Using "low" Tamil vocabulary and engaging in functional translation are both mechanisms that aim to increase the comprehensibility of the translation. For books intended to reach a village audience, comprehensibility starts before literacy. The kind of low, functionally translated Tamil vocabulary that is needed to reach this audience is not just for people with minimal formal education but supports those with no formal education to learn as well. Dr. Saleel Kumar, who is coordinating the Tamil translation of A Health Handbook for Women with Disabilities, emphasized the importance of using language an illiterate person can understand-so that they can be read to. "Even if you say [it in] Tamil, there are some things... the illiterate people will not be able to understand. So we have to keep the book in such a way [that] they will also be able to access [it]." The words in these books are not just for someone to read, but words for an illiterate person to hear: the translator is producing a text for the community health worker who reads the book aloud, as well as those listening. Each level of difference--of class, caste, education, and literacy, between the translator and the reader, and the reader and the listener--is considered and influences the production of a translation intended to speak across significant social distances. 
The translators recognize the distance between their and readers' lives and language in the way the translation is created and use vocabulary-such as appaa rather than thandhai for father-that acknowledges and attempts to bridge those distances. Specifically, they make an incommensurable difference-something that can't be measured across, and in this case words that would not be understood-into a difference that is represented in the language and construction of the text. Reaching across difference here is also a political move, reflecting both the pride of the translators in the Tamil language, and their insistence on creating published texts in language that can be understood by illiterate listeners. A postcolonial translation studies perspective highlights here the salience of this political move, as well as the fertile ground across which translation produces something that did not previously exist in either language: for example, the new term for edema that Sadhiq and Nisa created, translated as "water logging." The English word edema is neither self-explanatory nor motivating to someone not educated in medical English, whether in the US or Tamil Nadu. In creating their new vocabulary, Nisa and Sadhiq draw on colloquial language, producing not just a low Tamil text, but new language designed to be helpful to people with limited formal education. If we take seriously Sakai and Morris' propositions that translation makes something representable that was previously not representable, this type of low Tamil printed translation demonstrates the role that translation plays in the production of the health knowledges contained in its pages. Ramakrishnan and Saulina explain that a literal, high Tamil translation would produce a text that was readable and understandable to many individuals but would create neither the imagined equivalence nor access that many definitions of translation point to. By creating a functional and low Tamil translation, these translators make something visible and usable-not just the text, but the concepts contained within it-to a population that it otherwise would not be visible to.

\section{Make People Run}

As a health text, Doctor Illaadha Idaththil is meant to motivate people to take action-to go to the clinic or to stitch an open wound themselves when professionalized medical assistance is not available. Here, I extend the sociology of translation, which has not significantly engaged with health texts, to explore the unique aspects of knowledge production created in a text meant to create action in the world. Translators conceived of language as motivating action both in relation to the formal healthcare system, and within the community. Here, the salience of translating a Freirean health text comes through. This is a text that is meant to be used by anyone, regardless of formal training. To achieve its goal, it must inspire reflection and action. Translators consider the kinds of language, structure, and understanding that will encourage readers to set down the book and do something.

In the exchange at the beginning of this paper, Nisa and Sadhiq spoke of creating a new Tamil word for "edema" that people will understand--not just in a literal sense, but in a clinical sense. If the translation is successful, people who see fluid accumulating under the skin will interpret it as a sign of a potentially serious medical condition and seek care. Such creation of new language is a clear empirical example of the active role translation plays in the knowledge 
production process. This language is not just meant to be understandable, but to inspire action. This reflects Sakai's (1997) focus on the importance of recognizing realities created in and through language as hybrid and non-dualistic. In another example, Nisa recounted the creation of a new word for stroke:

[There] was "heart attack" ... we wanted the common man to give the same importance to "stroke," which was not happening. Heart attack, everybody was scared. Why not "brain attack"? So we changed "stroke" in Tamil [to "brain attack"]. There is no scare in that word, in Tamil. Then we made it a scary word. It became "muulaitthaakku (mūlaittākku)." That's how we could... make people run if you have a stroke--which, if you reach the hospital in time, can be stopped or reverted, depending upon what type of stroke it is.

In this and the edema example, Nisa described educating people about the importance of seeking further care and motivating readers to take immediate action. She wants people to be afraid of strokes and rush to the hospital, knowing that if they arrive in time the damage can be controlled. Rather than using the previous Tamil term for stroke (pakkavaadham), Nisa and Sadhiq created a new word to inspire a new reaction, just as they rejected the use of existing words for swelling used to describe edema (niirkoovai or muzhangkaal viikkam) in favor of niirviikkam. The creation of a new word to impel a specific action, when a word for the condition already exists, exemplifies how translators actively re-make the text so that people can take actions for health. The text must be changed to be translated, in a Freirean cycle of reflection and action: the value of sharing knowledge that is so central to the text helps to make clear the role translation plays as part of an ongoing knowledge production process. Nisa and Sadhiq create new vocabularychanging the text, and the language--in order to share it. The new vocabulary is informed by Nisa's background as a nurse and her husband Sadhiq's education as a pharmacist, their overlapping language fluencies in English and Tamil, and their experiences as publishers. It is not new in the sense of the concept of "stroke" being expressed in Tamil-Tamil phrases to express and respond to that experience presumably exist in Siddha ${ }^{6}$ and other forms of medicine, and the biomedical concept likely entered Tamil vocabulary with the arrival of British colonists. However, those words had to be learned as vocabulary, and then have the health-related action assigned to them. In contrast, this new vocabulary was created in the hopes of motivating a builtin response- to "make people run." The creation of this new vocabulary represents an additional step in the knowledge production process that started with the development of the original Spanish-language text in Mexico, was translated into American English in California, then adapted for Indian English in Delhi, and translated into Tamil.

The next example I offer describes action on a different scale, outside of the clinic, and in the realm of community action to support a child with disabilities. Namita Jacob, who coauthored and led translations and adaptations of Helping Children Who Are Blind, described seeing how parents would act upon receiving the Tamil translation:

${ }^{6}$ A system of medicine that originated in South India. 
If a parent is motivated, then it doesn't matter whether she is literate, it doesn't matter that she doesn't read, she will get someone who does... I just give [the book] to the parent and we see what happens. And everywhere, this was immediate, they would take it, put it down and spread it out, make it flat and they would call for not one, but all the literate people and they'd all come around and sit.

Namita goes on to tell the story of visiting a village where a child had been identified by the National Association for the Blind but had not yet started getting support. When she showed the book to the family, the child's grandfather read it aloud, "and meanwhile the village school teacher showed up and just listened." Afterwards, the teacher insisted that the blind child "attend school every day, and that they send him with the book. And after class, when all the other children were sent back, [the teacher] would read the book, and he would practice with the child." In this small village, Namita's visit was a notable event, and the teacher came by to see what was happening: when he heard the grandfather reading out methods for teaching blind children, he realized he could use the book as a resource to learn and teach.

This ceremonial group reading was something Namita witnessed repeatedly, and associates with a successful translation-one that draws people together to read and listen, and to put into practice what was learned. This pattern of reading, listening, and action indicates to Namita that she has done an effective job translating the book into language that can be understood and put into action. It is important that the resulting actions are not just downstream effects of the initial Spanish-language knowledge production but are effects of both the translation process and the knowledges produced when the translated book is read, heard, and used. This constructivist, postcolonial perspective on knowledge production decenters the book as a supposedly static or immutable object and emphasizes the actions that translators, readers, and listeners take as important parts of ongoing work. Namita sees the uptake of the book as a community process: not one person reading, but a group of people gathered, so that parents, neighbors, teachers, and others learn collectively—regardless of literacy—to support a blind child to learn and grow.

These books are often read aloud, discussed, and used in different ways by different people: this is by design, the Freirean pedagogy of a self-help health book. There are not two ways to read the texts--a false dualism of English and Tamil-but an endless fractal of interpretation and meaning, as Sakai suggests. This was true before the translation, and the hybridity and non-dualistic nature of how each person might react to the text is multiplied through the work of the translators. Each interaction--a community health worker reading to a women's group, a teacher reading late at night and planning the next day's lesson-represents another element in the knowledge production process.

\section{Every Word We Went Through with Different People}

The processes of selecting and creating vocabulary that readers can understand and act on works best when done in collaboration with readers. Translators hold perceptions of what imagined future readers will and will not understand. Because these perceptions may not be accurate, 
translators rely on people with less formal education for feedback. Sakai's $(2006,1997)$ insights point to the distance between actors-in this case, translators sitting in offices and future readers and listeners at home and in clinics-as the distance that indicates a need for translation in the first place. The process of gathering feedback to assess whether something has been created that can communicate across that distance depends on and replicates social hierarchies, as domestic employees, recipients of non-profit services, and community health workers of lower caste and class are asked to provide additional labor in the form of feedback. The voices of these people are mediated by the needs and interests of translators as their labor and knowledge is depended on for translation. However, this feedback process also recognizes the distinct value of the knowledge that people with less formal education carry. Laying out these actors in a way that pays attention to the distances between them, as well as to efforts to create language that will communicate across those distances, facilitates analyses of how these processes both reinforce and undermine hierarchical productions of knowledge.

Having tried to create a functional translation, using low rather than high Tamil vocabulary, the translators look for proxies for their intended audiences and gather feedback to assess whether their translation can be understood. This process is more or less formal. As described above, Saulina gathered feedback from a range of colleagues after completing the first draft of a translation. As part of this, she took an institutional approach, sending out excerpts of translated material in her non-profit's newsletter for health workers, along with a short quiz. This simple method of field testing allowed her to assess whether and how her core audience could read and understand the material. Because she was the executive director of a state-wide branch of a national non-profit, Saulina had networks of community health workers in the field-women who were literate, with some health training, but worked frequently with illiterate women. Here, many levels of difference are reproduced and depended on to create what is intended to be a helpful book: from Saulina, as the executive director of a non-profit, to community health workers the non-profit trained and supports, to people those community health workers care for and work with. Without these layers of difference there would be neither the same kind of need for translation, nor the same kind of book produced - a book that has been produced by Saulina, by community health workers, and by the people they serve.

The translation of Helping Children Who Are Blind provides a less formal example of gathering feedback. Seetha Raman, the volunteer editor who helped shift the initial translation by using words such as appaa for father, rather than the formal thandhai, describes the way she gathered informal feedback about language choice:

Every word we went through with different people. And the finished product I read out to as many people as I could... I have staff, this lady who cleans the house, another who helps me to cook, and as they were cleaning the house I would read out to them and say what do you understand or what do you not understand... And they would say "I don't understand this word" and then I would change it.

Seetha asked her house staff, who are from caste, class, and educational backgrounds closer to the imagined reader, to assess what language might be best understood. In doing this, 
she was drawing on the unique knowledge of women who worked for her: their labor was relied on twice over, as domestic workers, and as a sounding board for translation language choice. This pattern replicates social hierarchies of class, caste, and education, while also undermining them by explicitly valuing the knowledge of people who are usually presumed not to have valuable feedback for the publication of a widely-used book. The translation process draws on and values the knowledge of these lower caste women, while simultaneously demonstrating the distance between the translators and the people they hope to reach.

Namita, who has extensive experience working with communities to support children with disabilities, took Seetha's informal feedback-gathering to another level:

I live on [a university campus], we have a servants' quarters behind us. Many of the women, their children go to school but they dropped out [after] third grade and fifth grade and so on. I would have them proofread the Tamil and explain to me what needs to happen with the child. This was the way we made sure the language was ok.

She asked the women who lived and worked as servants in her building to read pages and describe to her what they would do, testing whether the first step of translation-understanding--would lead to the second--motivation. The women's knowledge and understanding were relied upon, but they were elicited across a heavily asymmetrical social hierarchy. This reflects what Sakai $(2006,75)$ describes as "the incommensurable differences that call for the translator's service in the first place" and mirrors the dynamic described above, simultaneously drawing on and ascribing value to the knowledge of women with less formal education.

Each translator uses the audience they have access to that best approximates the audience they are hoping to reach-caregivers of young children in the case of Helping Children Who Are Blind, and community health workers for Where There Is No Doctor. Those who give feedback become part of the translation process: although uncredited and uncompensated they are integral to creating a functional text and enabling translators to reach across social distance to future readers with little, if any, formal education. Translation here simultaneously replicates and undermines hierarchies of knowledge production, but also allows these texts to travel from Mexico, through the US, to non-profits run by medical, social work, and publishing professionals in India, and on to community health workers, teachers, and caregivers. The way that the books are adapted and edited, based on a recognition of the distance between readers, writers, and listeners facilitates their travels across social distances within and between distant locations. Postcolonial translation studies engage the hierarchies and distances between the many social locations through which the book travels, including the role of future readers, whose knowledge is relied on to both produce a text and to perform the care work that makes the desk work of translation possible.

- Hesperian has a formalized the field testing process: some Tamil translators had taken part in this, and others may have been influenced by it indirectly. 


\section{Terms Which Today Have Become Common Language}

The social process of creating new vocabulary to produce an understandable and motivational translation often results in the circulation of new phrases. This spread of new vocabulary is an instrumental move that helps to overcome situations in which previous language is perceived as insufficient. It is also a demonstration of the relationship between language and knowledge. Examining translation demonstrates ways in which language codifies knowledge and allows it to travel and act on the world, in turn reinforcing the key role that translation plays in a knowledge production process that starts, but does not end, with English-and in this case, originally Spanish-language texts. The process happens organically, through use of the books, but can be traced through the publishers that printed the first and third iterations of the Tamil version of Where There Is No Doctor. First, translators create new language, as Sadhiq and Nisa describe above. Then, they use it consistently in their own writing, creating internal lists and published glossaries. Over time the language circulates with the books and influences popular writing on health.

Ramakrishnan, who published the 1984 edition, describes what makes language in these books valuable and drives the creation of new vocabulary, reflecting views quoted earlier.

It is also a contribution to the language because many of the concepts that we discussed in Where There is No Doctor had not been properly expressed in Tamil until that. We found there are eleven terms in Tamil for dehydration, none of them scientifically accurate or simple or communicative. If you are introducing a word or concept, it must be simple to understand, easy to communicate, and scientifically sound. In the process we introduced a set of terms which today have become common language, like dehydration or suppository or antibiotic or diaper.

He is concerned that words point to a specific meaning. Since none of the existing words fits his criteria, he coined niirizappu, or "loss of water" for dehydration. There may be words currently in the language--many terms for dehydration, as well as "swelling" for edema and a literal translation of "stroke." However, Ramakrishnan reflects Nisa's concerns that the words in this text should generate what he sees as the right kind of understanding in people. This creation of vocabulary is a profound aspect of the knowledge production process in which translation plays a role. A literal translation might take up the most common of the previously used words, but this functional, low-Tamil translation produces a new word intended to communicate a different kind of understanding.

As new vocabulary is created, that vocabulary becomes codified. The first level at which this happens is in internal lists created by and for the translators. Sadhiq founded his press in 1998. He considers Ramakrishnan to be one of his gurus and took up translating Where There Is No Doctor when the previous edition had become outdated and unavailable. Sadhiq and Nisa, who describe coining new words for "edema" and "stroke," have created their own glossary of codified language. Nisa describes their internal list as a "data bank that we have made." Over time it became second nature to them, to a point where they no longer looked words up, but 
implemented a standardized set of vocabulary across publications. In a knowledge production process, this level of internal codification is important: before sharing a new conceptualization or representation with the world, it is recorded and used by those who created it. The second level of codification is external and can be traced in published books.

To maximize readers' comprehension of the first Tamil translation, Ramakrishnan added a two-way language glossary. The reader, he explains, may "know an English term but may not know the Tamil term. Everything would be in Tamil, so we had a two-way glossary, TamilEnglish, English-Tamil." The glossary, included in the current edition, makes the book understandable to a wider audience, as readers have overlapping but varied English and Tamil vocabularies. This acknowledgment of the multi-lingual nature of Indian education and medical pluralism that mark India's pronounced heterogeneity is an example of the kind of knowledges that Sakai (1997) and colleagues see produced in translation, creating difference rather than equivalence out of incommensurability. It acknowledges the diversity of Tamil readers who will pick up the book. For some, Tamil will be their first language; for others their second or third. Some readers will have been educated in Tamil-medium schools, others in English, others in a combination of both. Finally, some readers may have learned Tamil at home but been educated in a third language, such as Sri Lankan Sinhalese. This linguistically diverse population the translators hope to reach undermines the idea of thinking about translation as replacing one phrase with another and imagining the word or phrase will create the same reaction in a different place. The need for the glossary reflects the heterogeneity of readers, as well as the variety of knowledges leveraged and produced in the translation, reading, and use of the book.

The published glossary, reprinted and edited many times between 1984 and 2013, becomes part of the circulation of this vocabulary. Approximately 60,000 copies of Tamil translations of Where There Is No Doctor have been distributed. Ramakrishnan's press is well known for its Tamil dictionary, and his commitment to his role as someone who maintains and builds Tamil literature is strong. He sees his work in Where There Is No Doctor as a "contribution to the language," and reports seeing terms he coined, including anaiyaadai for diaper and utkaraikkulihai (uțkaraikkulikai) for suppository, used later in popular writing on health. As Sadhiq and Nisa create new language for "edema" and "stroke," they feel this new vocabulary is being taken up and used. They began publishing the book in 2011, so at this point the language is unlikely to have spread in the way Ramakrishnan describes his terms becoming part of health vocabulary.

From Ramakrishnan's work in the 1980's through the most recent edition of Where There Is No Doctor, translators are creating and circulating vocabulary--not always to translate something that has never been translated, but to communicate a specific idea about health that will produce new possibilities for action. New vocabulary is created, not to name the un-named but to describe it in a way that is simultaneously comprehensible and motivating for its intended audience. Next it is codified in internal and published glossaries, and spreads with the books. Like many other Indian language editions, these cross borders, notably to Sri Lankan Tamilians who often lacked access to health care before, during, and after the civil war. Each language edition travels, and each is a location in which unique parts of the knowledge production process 
take place. These translated forms of health knowledge are not bound by or defining of a nationality or a specific medical setting (Sakai 2006). Translators are constantly creating, in new words, and new languages, a text that originated in North America and is re-produced around the world.

\section{Conclusion}

The purpose of these books is to reach people with minimal formal education, and to motivate them to take action to improve their health. Direct translation almost always "raises" the level of the language, making it illegible to the intended audience and unlikely to inspire them to act. Therefore, to make a translation that accomplishes what the text intends, translators must continue to work with the translated language. This case study-these Freirean health texts, and the low/high diglossia of the Tamil language-brings out a process I propose is happening in other translations but is made especially clear here. The effort to find and create language that communicates the health text in another language highlights the work done by translators, and the ways in which translation is a key part of an ongoing knowledge production process. This interpretation of translation leverages knowledge production in a non-typical way but is in line with critical perspectives looking to expand analyses of how and where knowledge is produced, and the power dynamics that shape and are shaped by such ongoing production.

From Namita's team of volunteers and neighbors to Saulina's newsletter readers, these books are created through social relations. At the center of the arena of health, community, and texts this paper traces are the translators and imagined readers: community health workers, caregivers, and teachers. The distance between these actors and their written and spoken words propels the ongoing production of health knowledges. However, this process both draws on and values the experience of women with limited education and confirms their social distance from the translators. A successful translation relies on the labor of these women, always filtered through the understanding of those with more education and socio-economic status. Knowledge is always produced across hierarchies. Here, the effort to reflect the experiences of the subaltern reflects the Freirean values of the books. However, it is never complete. During the exchange, the women are not given, for example, the education to then write such materials themselves. A sociology of translation focused on macro-level social processes would engage these interactions on their own terms: a sociology of translation that employs ANT recognizes the books as actants but risks flattening the relations across which they are produced and travel. By engaging postcolonial translation studies, this analysis tracks not only the social relationships between books, translators, and readers, but also the friction with which these travel, and the health knowledges produced in the process.

Nisa and Sadhiq create language to encourage individuals and clinicians to intervene on bodies. For Namita, this intervention extends to social networks. In the process of creating and popularizing language that readers will understand and act on, new vocabulary is created and circulates. Kathy Davis (2007) sees a similar pattern in her analysis of the production and translation of the seminal women's health text Our Bodies, Ourselves. She describes translators 
changing or making up new words that reflect a positive, rather than shame-based understanding of women's bodies, referring to this process of creating new language to "reclaim women's bodies" as "linguistic innovation" (Davis 2007, 171). I saw similar patterns across other language translations: a study of the production of new vocabulary through health and other translation would provide an important window into how knowledges are produced in the effort to recognize and communicate across difference. Such a study might also engage with the next step in this process: how new language travels and is used.

What is translated in these books, similar to what Davis sees in Our Bodies, Ourselves, is a set of ideas: a belief that people can understand their own bodies and be motivated to act. Translators emphasize that direct translation would not be sufficient because language varies across culture, class, caste, and education. In the incommensurability between life experiences and languages of imagined audiences and translators, translation becomes part of the ongoing production of health knowledges. It creates a text that is both related to and distinct from other language editions. This paper tells one piece of a story about books that have traveled the world, picked up by individuals and communities, translated, carried, become dog-eared with use, left on a shelf, reprinted, redrawn, and now digitized. It provides a case study about the kind of knowledge in the books, and how it is produced. It is the kind of knowledge that is meant to speak to readers where they are, to be immediately useful, and to give people the tools they need to set down the book and act.

\section{Author Biography}

Lillian Walkover received her PhD in Sociology from the University of California, San Francisco (UCSF) in 2018. A sociologist of global health with an interdisciplinary orientation, she has experience conducting qualitative global health research in the US and abroad. She focuses on the production, valuation and movement of health knowledges, both globally and in the US. Her doctoral work focused on how health knowledges are produced and travel through an analysis of the translation and adaptation of "Where There Is No Doctor," the most widely used health manual in the world. This project explored translations and adaptations in Hindi, Tamil, Kannada and English for use in India, and the analysis sits at the intersection of sociology of health and illness, critical global health, and postcolonial science and technology studies. In addition, she works with the Structural Competency Working Group to use structural competency and other social science frameworks for health professions education. Her postdoctoral research at Drexel University with Susan Bell, PhD, is a study of the experiences and career paths of physicians who enter the US as refugees.

\section{Acknowledgments}

Thank you to the translators interviewed for this study for your time and insight. Thank you to Janet Shim, Ariana Thompson-Lastad, Emily Treleaven and Maryani Rasidjan for your guidance while developing this paper. Thank you to the anonymous reviewer, and to Katie Vann and 
Daniel Kleinman for your invaluable comments. This material is based upon work supported by the National Science Foundation Graduate Research Fellowship under Grant No. 1650113. Any opinion, findings, and conclusions or recommendations expressed in this material are those of the authors and do not necessarily reflect the views of the National Science Foundation.

\section{References}

Anderson, Warwick. 2009. "From Subjugated Knowledge to Conjugated Subjects: Science and Globalisation, or Postcolonial Studies of Science?" Postcolonial Studies 12 (4): 389-400. https: / / doi.org/10.1080/13688790903350641.

Biehl, João, and Adriana Petryna. 2013. When People Come First: Critical Studies in Global Health. Princeton University Press.

Buzelin, Helene. 2007. "Translations 'in the Making.'" In Constructing a Sociology of Translation, edited by Michaela Wolf and Alexandra Fukari, 135-69. Amsterdam; Philadelphia: J. Benjamins Pub. Co.

Census of India. 2011. "Census of India: India at a Glance." 2011. http:/ / www.censusindia.gov.in/Census_Data_2001/India_at_glance/glance.aspx.

Chakrabarty, Dipesh. 2000. Provincializing Europe: Postcolonial Thought and Historical Difference. Princeton University Press.

Charmaz, Kathy. 2014. Constructing Grounded Theory. 2nd ed. Sage.

Clarke, Adele E., Carrie Friese, and Rachel S. Washburn. 2017. Situational Analysis: Grounded Theory after the Postmodern Turn. 2nd ed. Sage.

Davis, Kathy. 2007. The Making of Our Bodies, Ourselves: How Feminism Travels across Borders. Durham, NC: Duke University Press.

Freire, Paulo. 1970. Pedagogy of the Oppressed. New York: Herder and Herder.

Gambier, Yves, and Luc van Doorslaer, eds. 2010. Handbook of Translation Studies: Vol. 1. Amsterdam: John Benjamins Pub. Co.

Hesperian. 2013. "Impact I Hesperian Health Guides." April 22, 2013. http://hesperian.org/about/impact/.

Krishnamurti, Bhadriraju. 2011. "Tamil Language | Britannica.Com." Encyclopedia Britannica. 2011. https:// www.britannica.com/topic/Tamil-language.

Latour, Bruno. 2007. Reassembling the Social: An Introduction to Actor-Network-Theory. Vol. 1. New York: Oxford University Press.

Morris, Meaghan. 1997. "Foreward." In Translation and Subjectivity: On "Japan" and Cultural Nationalism, ix-xxii. Minneapolis: University of Minnesota Press.

Sakai, Naoki. 1997. Translation and Subjectivity: On "Japan" and Cultural Nationalism. Minneapolis: University of Minnesota Press.

—_. 2006. "Translation." Theory, Culture \& Society 23 (2-3): 71-78.

Star, Susan Leigh. 1990. "Power, Technology and the Phenomenology of Conventions: On Being Allergic to Onions." The Sociological Review 38 (S1): 26-56. https: / / doi.org/10.1111/j.1467-954X.1990.tb03347.x. 
Tsing, Anna Lowenhaupt. 2005. Friction: An Ethnography of Global Connection. Princeton University Press.

Werner, David, Carol Thuman, and Jane Maxwell. 2009. Where There Is No Doctor. Berkeley, CA: Hesperian Health Guides.

Wolf, Michaela, and Alexandra Fukari, eds. 2007. Constructing a Sociology of Translation. Amsterdam; Philadelphia: J. Benjamins Pub. Co. 